\title{
Does coercion matter? Supporting young next-of-kin in mental health care
}

Elin Håkonsen Martinsen (1)

University of Oslo, Norway; Vestre Viken Hospital Trust, Norway

\section{Bente Weimand}

Oslo Metropolitan University, Norway; Akershus University Hospital, Norway; Queens University Belfast, Northern Ireland, UK

\section{Reidun Norvoll}

Oslo Metropolitan University, Norway; University of Oslo, Norway

\begin{abstract}
Background: Coercion can cause harm to both the patient and the patient's family. Few studies have examined how the coercive treatment of a close relative might affect young next-of-kin.

Research questions: We aimed to investigate the views and experiences of health professionals being responsible for supporting young next-of-kin to patients in mental health care (children-responsible staff) in relation to the needs of these young next-of-kin in coercive situations and to identify ethical challenges.

Research design: We conducted a qualitative study based on semistructured, focus group interviews and an individual interview.

Participants and research context: We held three focus group interviews with six to seven childrenresponsible staff in each group (a total of 20 participants) and one individual interview with a family therapist. The participants were recruited from three hospital trusts in the eastern part of Norway.

Ethical considerations: The study was approved by the National Data Protection Official for Research and based on informed consent and confidentiality.

Findings: Coercion was not a theme among the participants in relation to their work with young next-ofkin, and there was much uncertainty related to whether these young people need special support to deal with the coercive treatment of their close relative. Despite the uncertainty, the study indicated a need for more information and emotional support among the youth.

Discussion: Few studies have addressed the potential impact of coercive treatment of a close family member on young next-of-kin. The findings were consistent with existing research but highlighted disagreement and uncertainty among the children-responsible staff about to what extent the young next-of-kin should visit and whether they should enter the ward unit or not. We identified ethical challenges for the children-responsible staff related to the principle of not inflicting harm (nonmaleficence). Conclusion: From the perspective of children-responsible staff, it appears that the coercive treatment of a close family member entails a need for extra support of young relatives both in relation to information and the facilitation of visits, but more systematic knowledge about these issues is needed.
\end{abstract}

Corresponding author: Elin Håkonsen Martinsen, Child and Adolescent Psychiatric Department (BUPA), Division of Mental Health and Addiction, Vestre Viken Hospital Trust, Drammen 3004, Norway.

Email: elin.h.martinsen@gmail.com 


\section{Keywords}

Coercion, ethics, family support, mental health services, young next-of-kin

\section{Introduction}

The use of coercion is a relatively common phenomenon in mental health care. The concept of coercion includes formal coercion (e.g. legalised use of involuntary hospitalisation or forced medication), informal coercion (e.g. pressure and threats) and the structural and cultural aspects of power, such as locked wards and paternalistic cultures that contribute to shaping a coercive context for patients. ${ }^{1}$ Although the intent of coercion is to reduce danger and harm to the patient, a substantial body of research has found that coercion also has the potential for causing psychological, physical and social harm to both patients and their families. $^{2-4}$ This makes coercion a high-risk intervention that demands special considerations and prevention.

Research on adults, both patients and next-of-kin, has shown that the use of coercion, such as involuntary hospital admissions, forced medication or mechanical restraints, can create conflict and distrust among family members. ${ }^{5}$ Research has also shown that health care professionals experience many challenges regarding the involvement of adult next-of-kin in coercive situations related to confidentiality, ambiguity, guilt, shame and experiences of stigma. ${ }^{6-8}$ These challenges may create barriers for the other family members to be involved in the treatment and follow-up of the patient, ${ }^{2,9,10}$ thus implying that the use of coercion needs to be considered in a broader family perspective. ${ }^{5,11}$

Studies have clearly shown that the children of parents with serious mental health problems face many developmental, emotional, behavioural and educational challenges and are at risk of developing mental health problems themselves. ${ }^{12-16}$ Therefore, health personnel should ascertain what kind of support measures these children need and start the necessary follow-up. ${ }^{17,18}$

In Norway, about $15 \%-20 \%$ of all hospitalised patients are involuntarily admitted (about 5000 adults). ${ }^{19}$ There are similar occurrences internationally, although there are variations in the use of involuntary admission among countries. ${ }^{20}$ To the best of our knowledge, there are no general statistics regarding how many involuntarily committed patients have minor children or siblings. Presumably, a significant number of these patients have close family members who are minors. Yet although there are established research traditions relating to children and siblings of persons with mental health problems ${ }^{12-18}$ and to coercion in mental health care, ${ }^{3,20-23}$ few studies have focused on how children might be affected by a coercive commitment of a close relative to a hospital. Research has not explored the risks of harm and the needs of children in such families, nor how young next-of-kin should be supported when a close family member, parent or sibling undergoes forced treatment.

Among the previous research, one study has addressed the impact of the hospitalisation of a close family member on young next-of-kin, including their encounters with 'locked wards', thus implicitly describing involuntary admissions. ${ }^{24}$ Another study conducted as part of this research project (see the study context) found that young next-of-kin experience many concerns regarding the involuntary admission of a parent or sibling with mental health problems; children described a lack of information about coercion, a lack of contact with their close relative and scary experiences both before and after the admission. ${ }^{11}$ The study revealed that health personnel did not provide support for young people when their family members were involuntarily hospitalised. To the best of our knowledge, no studies have specifically explored the views and experiences of health care personnel regarding follow-up with young next-of-kin in coercive situations. However, research has shown that health personnel find it difficult to talk with patients about their children and to talk with the children themselves. ${ }^{25}$ Hence, more knowledge is needed regarding staff views and experiences and the possible dilemmas they experience in working with these children and youth. 


\section{Study context}

This study is part of a large-scale project in Norway called 'Mental healthcare, ethics, and coercion' (PET), which took place from 2011 to 2016. The main project aimed to address the ethical challenges regarding the use of coercion by exploring stakeholder's views and experiences with coercion and involvement in care.

Mental health care in Norway is publicly funded and organised as 'specialised health services' (i.e. hospital trusts (HTs) including hospitals and outpatient clinics) and as decentralised 'community health services' (i.e. general practitioners, local emergency care and home care). ${ }^{26}$ Formal coercion is mainly performed in specialised health services, and involuntary patients are referred by an independent physician who has to examine the patient personally and find that the criteria for involuntary admission are met. The patient is further assessed by a specialist at the hospital who decides whether the legal criteria are being met. $^{26,27}$

Similar to international trends, there has been an increased focus on the needs of children belonging to parents with mental health problems. ${ }^{12-18}$ Consequently, in 2010, Norway added two legislative provisions that oblige health personnel to attend to minor relatives and to designate children-responsible staff (CRS). ${ }^{28,29}$ The responsibilities of CRS are to promote and coordinate health personnel's follow-up with patients' minor children. ${ }^{29}$ Starting in January 2018 , these regulations were expanded to include minor siblings and children who have been bereaved. ${ }^{28,29}$

These overarching trends were also present in the three participating HTs, which discussed an increased focus on children as next-of-kin. Yet, the hospitals had different traditions and cultures for working with minors. Although HTs 1 and 2 had a long tradition of working with minors through local projects and 'enthusiasts', HT 3 was more focused on child-protection services.

\section{Aims and research questions}

The aim of this study was to generate knowledge about health personnel perspectives on the support of young next-of-kin during and after the involuntary treatment of a close family member. We conducted a qualitative study of the views and experiences of CRS with the following research questions:

1. What are the needs of young next-of-kin when their close family member undergoes coercive treatment?

2. In their everyday practice, how do CRS support young next-of-kin during the coercive treatment of a close family member? What are the challenges in providing support to young next-of-kin during the coercive treatment of a close family member? Are there ethical challenges?

Here, by 'ethical challenges', we are referring to the situations or problems that evoke doubt, uncertainty or disagreement about what is right or good. ${ }^{6,23}$

\section{Materials and methods}

\section{Participants}

We conducted three semistructured focus group interviews (six to seven health professionals in each group) in three HTs in the eastern part of Norway and one individual interview with a course leader for psychoeducational family therapy. We chose the focus group method because it allows participants to interact with each other, thus producing more information than other methods. ${ }^{30-32}$ 
Table I. Overview of CRS and ward types at the participating HTs.

\begin{tabular}{|c|c|c|c|}
\hline & HT I & HT 2 & HT 3 \\
\hline $\begin{array}{l}\text { Place } \\
\text { Ward type }\end{array}$ & $\begin{array}{l}\text { Rural HT } \\
\text { - Security ward } \\
\text { - Acute ward } \\
\text { - Outpatient clinic }\end{array}$ & $\begin{array}{l}\text { Rural and urban HT } \\
\text { - Ward for psychosis } \\
\text { - Emergency unit } \\
\text { - Ward for affective disorders } \\
\text { - Community mental-based health } \\
\text { centres (with both outpatient and } \\
\text { inpatient services) }\end{array}$ & $\begin{array}{l}\text { Rural and urban HT } \\
\text { - Outpatient clinic } \\
\text { - Acute ward } \\
\text { - Ward for affective } \\
\text { - disorders } \\
\text { - Ward for psychosis } \\
\text { - Youth ward }\end{array}$ \\
\hline CRS & $\begin{array}{l}\text { Social workers, nurses, } \\
\text { social educators and } \\
\text { assistant nurses }\end{array}$ & $\begin{array}{l}\text { Social workers and nurses with further } \\
\text { education in mental health/family } \\
\text { therapy }\end{array}$ & $\begin{array}{l}\text { Social workers and nurses with } \\
\text { further education in mental } \\
\text { health/family therapy }\end{array}$ \\
\hline
\end{tabular}

CRS: children-responsible staff; HT: hospital trust.

A combination of purposive and convenience sampling of health professionals was used. The inclusion criterion was being a transdisciplinary health professional holding position as a CRS in hospital services and outpatient clinics. Because of their position and experience with working with young next-of-kin, the CRS were regarded as key informants (purposive sampling). Because of limited resources, we chose hospitals in the eastern part of Norway, where we already had contacts (convenience sampling). This recruitment strategy ensured the inclusion of particularly well-informed health personnel (i.e. key informants) who could provide valuable insights and a variety of views and experiences. ${ }^{33,34}$ The sample consisted of $20 \mathrm{CRS}$ from different kinds of services and wards at the HTs described above (Table 1). We also included one individual interview with a family therapist working as a course leader for psychoeducational multifamily groups as a key informant. We interviewed her prior to the focus groups to gain some insight into the field and considered her experiences as relevant and important for this study.

As described in Table 1, 12 participants from hospital services representing nine wards participated in this study. From the decentralised services, six participants represented one outpatient clinic, two community mental health centres and three other services such as education and staff. The participants were recruited, and interviews were conducted between January and May 2014. The participants were recruited through staff responsible for the research and development and through coordinators for CRS in the HTs.

\section{Data collection}

Using an interview guide created by the study's authors, the interviews lasted for approximately 60-90 min. The interview guide was inspired by the main project, as described in the study context. We asked the participants about existing supports and follow-up for young relatives in coercive situations. We also asked about their reflections regarding information needs, involvement in the treatment of their close relative and possible ethical dilemmas.

The individual interview was conducted by the first author. The focus group interviews were conducted by two authors. One of the authors acted as a moderator to ensure that all voices were heard. The other researchers supplemented the other authors during the interview, offering follow-up questions.

During the interviews, we spent some time getting an overview of how the CRS worked. Then, we asked for their specific views and experiences related to coercion and, later, ethical challenges. There was a clear break in the interviews when we asked about coercion, experiencing that the participants had few explicit thoughts and opinions on coercion as a theme related to young relatives. At this point in the interviews, we had to deviate from the interview guide and ask more focused questions regarding coercion. 


\section{Analysis}

We performed an inductive thematic content analysis. ${ }^{35}$ To ensure rigour, we followed the steps of systematic text condensation proposed by Malterud. ${ }^{36,37}$ The interviews were recorded and transcribed verbatim in Norwegian. The analysis proceeded in the following stages: (1) reading all the material to obtain a general impression of the whole. (2) Identifying units of meaning that represented different aspects of the participants' views and experiences of working with young next-of-kin in coercive situations and coding for these. The meaning units were then arranged in data matrices for comparative analyses across interviews and in relation to the interviews as a whole. (3) Condensing and abstracting meaning units within each coded group. (4) Summarising the contents of each coded group to generalise descriptions, reflecting the most important aspects of the informants' views and experiences related to supporting young next-of-kin. These descriptions are presented in the 'Results' section together with selected illustrative quotations.

The three authors met regularly throughout the analysis process to ensure reliability. The interviews were read and interpreted independently by the co-authors, and the findings were subsequently discussed. When there was disagreement or uncertainty concerning an interpretation, the authors returned to the original transcripts to examine the quotes and the text condensations in context and then further discussed the material until agreement was reached. In the last analytical stage, we assessed the relevance of our findings by comparing them to existing empirical studies and theories.

\section{Research ethics}

The study was conducted in accordance with the Helsinki Declaration, including informed written and oral consent and confidentiality. In accordance with Norwegian law, the study was formally evaluated by the Regional Committees for Medical and Health Research Ethics, ${ }^{38}$ which decided the study was outside their field of responsibility because it was regarded as 'health service research'. The study was therefore assessed and approved by the National Data Protection Official for Research. ${ }^{39}$

\section{Results}

The focus group interviews revealed that there was neither a discussion nor any policies or procedures for supporting young next-of-kin in coercion-related situations, even in ward units with frequent use of coercion. The interviews furthermore revealed significant uncertainty and some disagreement among the participants as to whether these young people had specific needs for support from health personnel related to the coercive treatment of their relative and, if so, what good support meant. During the analyses, we identified three themes in which this uncertainty was expressed: (1) uncertainty related to the impact of coercion on young next-of-kin, (2) uncertainty related to providing information about coercion, and (3) uncertainty related to the degree of involvement that is appropriate for young next-ofkin when close family members are admitted involuntarily. Based on this thematisation, we present the findings in three sections.

\section{Uncertainty related to the impact of coercion on young next-of-kin}

Coercion not being a theme. Coercion as a theme had neither been discussed nor been an explicit focus in the participants' work related to young next-of-kin. As one participant remarked, 'So I think that just with coercion, I see, it has not been a huge theme in relation to how I have worked'. Several participants believed that coercion was a term most familiar to health personnel and thought that the concept might be hard for children and adolescents to understand. The participants had not experienced any demands for information about coercion from the young next-of-kin or from family members in 
family-oriented treatment. There were no specific policies related to support for young next-of-kin in connection to involuntary admissions or the use of coercive methods, such as forced medication or mechanical restraint at the ward unit.

Nevertheless, one of the participants reflected on how coercion might affect children and youth by them having to face and handle both anger and conflict related to the involuntary treatment of their close family member:

I think that, in many of those cases where coercion is involved, it is experienced as a violation, right? [...] And then, when they come back to the children and are still angry and think it's totally unreasonable [...] The children get something extra there then compared with others that are voluntarily admitted, in a way [...] Coping with all that anger.

Coercion appeared in practical experiences. Even though coercion was seldom discussed nor reflected upon, the participants described concrete situations from their practices of how young next-of-kin experienced the use of coercion. For instance, by witnessing involuntary hospitalisations and dramatic admissions with the involvement of the police or seeing locked doors and barred windows at the hospital. One participant commented on how children and youth visiting the department could be negatively affected by the physical environment, finding it 'creepy':

There may be kids visiting who have been concerned that the doors are locked, that there is a grid in front of the window. Um, that such things are creepy, and that it requires an explanation. But the coercion itself, I simply have not identified that as a specific theme I must say.

The participants also received questions from young people related to whether their close relative could leave the department or go home on leave. A social worker at a psychiatric security department described a meeting with a girl asking about her father:

I got a question on the activity day that we had. The girl who was there, I asked if there was anything she wondered about, also in relation to her dad. She knew the hospital a bit, but she asked me, 'Can he come home on leave'? So I had to explain to her a bit, how he was doing with the illness and [ ... ]. So that was a kind of, what to call it, a coercion question. I had to explain to her that we had to decide when he was well enough.

\section{Uncertainty related to providing information about coercion}

Is it necessary to inform young next-of-kin about coercive measures? There were different opinions and uncertainty among the participants regarding whether it was necessary to inform the young next-of-kin specifically about coercion. This was not a theme on which they had previously reflected much.

Some of the participants were uncertain if the young people would notice whether their close relative was admitted involuntarily or not and hence questioned whether it was necessary to inform them about coercion specifically:

It's not certain that kids think so much about that, I think, if you are in hospital, you're in hospital, whether it's voluntary or forced. [...] They do not know what it is, nor the difference between them, of course not.

The participants thought it was more important to address the whole picture of the illness rather than just focusing on coercion because it was the expression of the illness and the behaviour that often affected the young next-of-kin most. 
Many of the participants were sceptical of the idea of informing children about coercive admissions, being concerned that it would be harmful for the children to get the information, especially if the child did not live with the sick parent:

Should we have called a child and told that mum was involuntary admitted and about what has happened in a coercive episode? One can think of it oneself, that I didn't think it was any good either.

On the contrary, other participants pointed out that young people also would need information about what to expect when visiting the hospital (i.e. seeing locked doors and barred windows):

It is quite natural, I think, if you drag the kids into a closed department with locked doors and grids for the window, then I think we must say something about it. Why it is like that. That here are the people who may not $[\ldots]$, cannot take proper care of themselves at the moment, and therefore, it is important that they are properly looked after.

One of the participants who had personal experiences of being a young next-of-kin in psychiatric health care stressed the importance of not placing the responsibility of addressing coercion on young relatives but rather on health personnel. By not addressing the issue of coercion explicitly, health care personnel maintain the stigma and shame connected to coercive treatment: 'And I might think that as health care professionals, we help maintain the stigma by not talking about some topics'.

Lack of consent to inform - how to manage? Most participants stated that patients did not always provide consent to provide information to the young next-of-kin:

I'm thinking of a 17-year-old. The son made contact himself, [... ], 'my dad is hospitalised, and I don't get to know anything'. What do we do then? So, we are allowed to inform in general then, but not further go into it.

Several participants stressed that a lack of consent for sharing information did not mean that they could not speak to young people more generally about mental illness, the diagnosis or about being a young nextof-kin:

[...] It is often more about confirming what [the young next-of-kin] have already seen. So it's not necessarily so that we should tell them what diagnosis their parents have or [...]. But it's more that $[\ldots]$, that they can get confirmation of that; yes, that has to do with the illness. That they can get some answers to some questions.

Fear of involvement from child welfare services or complicated family situations with, for example, divorced parents, were often the reasons for the lack of consent. Many participants had found that it was helpful to ask for consent to inform several times during the hospital admission because it changed depending on the patient's condition. However, the participants found it difficult to get acceptance from colleagues for spending time to obtain such consent because this was seen as a time-consuming effort that could detract from other tasks.

\section{Uncertainty related to the degree of involvement appropriate for the young next-of-kin}

Call for a meeting or leave alone? There were different opinions among the participants regarding how proactive they should be in initiating contact with the young next-of-kin. Some reported that they occasionally did not initiate contact but rather waited for the young next-of-kin to take the initiative, giving them time to gather themselves at home: 
I notice that there are some relatives coming thinking it's really nice when they can go home and sleep because they have not done that for the last three months $[\ldots]$. That they need $[\ldots]$ and that we recognise that need. That's okay.

At the same time, several of the participants were concerned that young next-of-kin did not necessarily know what their own needs were in such situations and that they should hence be offered information and invitations to visit the hospital.

Some of the informants had received feedback regarding siblings who wished to be contacted by health care professionals:

We have received such feedback afterwards, that we have not contacted the siblings [...] we think we have spared them, instead we have made them feel left out. And after some years, they start thinking that they also should have been included earlier.

Inside or outside the ward unit?. The participants expressed different views on whether to allow young next-ofkin to enter the ward unit or not. The practice on this matter varied between the HTs involved and also between the different departments and ward units within the same HT. Variations in practice were not attributed to the type of ward unit (i.e. acute or intermediate).

In some departments, it was considered important that young people were allowed into the ward unit to see how the family member was doing. The participants thought that seeing how the parent or sibling was faring in the ward unit was positive - that the parent or sibling was safe and well, 'drinking coffee as usual'. One of the participants expressed it in the following way:

To get a picture of the room. [...] That means more than starting to talk about the expressions of the illness, using fine words that no one understands at all. If you start there and create something that makes them certain that mom is in a safe place.

To achieve this in a positive way, the participants stressed the importance of timing, planning and sufficient staffing to handle difficult situations that might arise and to avoid disturbing other patients in the department.

Conversely, the other participants described other practices and approaches where young people were not allowed to enter the ward unit but had to meet their family member in separate visiting rooms. They emphasised that this was for the sake of both the young person, who might be scared by seeing seriously ill patients inside the ward units, and the other patients, who require protection and discretion:

So it is the case with situations in the ward unit, right? And then there are a lot of sick people inside an acute unit, so it's like you say very scary to the kids, so it's okay to get them outside. [...]

Then it is the other patients, who are in the ward unit, it is not always okay for them that mother and father and grandfather and two kids come in, somehow, being seen. Must attend to the other patients also.

The participants mentioned how important it was for many of the patients to maintain their parental roles in meeting with their children. In connection with this, one participant told of a mother being admitted who wanted to shield her son from seeing her when she was at her worst. Nevertheless, in cooperation with the staff, she managed to have her son come to visit her in her room, which turned out to be a positive experience for them both: 
On his second visit, the son was allowed to come in and see his mom's room. And his mom was surely affected by her illness, but at the same time, she had a lot on the walls, so it was really exciting inside. But what was alright to hear was that when the son went home and called her afterwards, mom could say something about what she was doing and where she was sitting in the room. And it created a safety [...], and again, I actually got confirmation of how important it is bringing the children in so they can see where mom is.

\section{Discussion}

\section{Methodological considerations}

This is a small study, and more research is needed. Yet given the lack of previous studies, this research adds valuable knowledge for the support of young next-of-kin experiencing a close family member undergoing coercive measures, and it may stimulate further research regarding these concerns. Even though the data are 5 years old, there are only a few recent studies exploring similar problems., ${ }^{711,24}$

By interviewing the CRS, we gained access to key informants in the field. However, additional observational data on how CRS deals with these challenges in practice would have been beneficial. Furthermore, we do not have any information about the views of the young next-of-kin themselves; this represents an important limitation of the study and implies that there is a need for more research in the field.

As described earlier, we introduced a theme that was little discussed among the participants. Therefore, it could be said that we influenced the information gathering by 'fishing for' answers. Retrospectively, it might have been better to structure the interviews in relation to a specific case story or ask more focused questions rather than asking openly, to help the participants stay 'on track' in a previously unknown field.

It is also possible that differences in the prevalence of coercion at the different departments and ward units may have influenced our results. We know that there are variations in the use of coercion; however, this variation was not the focus of this study. Rather, we focused on the phenomenon of coercion and how it relates to the support of young next-of-kin.

\section{What needs do young next-of-kin in coercion-related situations have?}

In this study, we asked for the views and experiences of CRS regarding whether young next-of-kin have specific needs when coercive measures are being used. An overarching finding of this study is that the participants are unsure about the importance or moral necessity for the young next-of-kin to learn about the coercive treatment of their close family members. However, despite this uncertainty, the participants also described the impact of coercion on young next-of-kin: the youth were reported as having questions that were important to clarify or previous experiences that had made them frightened.

There is little research about providing support to young next-of-kin when their family member undergoes coercive mental health treatment. This study confirms the findings from previous research ${ }^{11,24}$ that young next-of-kin need more information about their family's mental health status and treatment. This study also indicates a need for more specific support among the young next-of-kin related to the coercive treatment of their close relative. Thus, the results from this study are consistent with the findings from the main project (PET). ${ }^{11}$

However, the previous article in the main project found that young next-of-kin wanted more contact with their family members during hospital admittance. ${ }^{11}$ To a certain degree, this point diverges from the findings in this study, in that there were different views and uncertainty among the participants about whether the young next-of-kin wanted to have distance or more close contact with their close relatives during times of admittance. The uncertainty and diverging views reflect a moral uncertainty related to the task of providing good care for children and youth, as discussed in the next section. 


\section{Ethical challenges}

The findings actualised the ethical challenge of not inflicting harm by 'exposing' youth to psychiatric ward units, highlighting the ethical principle of nonmaleficence. ${ }^{40}$ What does proper support of young next-ofkin in these situations actually involve, and what may be most damaging to the youth (i.e. knowing or not knowing? seeing or not seeing?)? Furthermore, in what situations is it most proper to do it the one way or another - both clinically and ethically? More systematic knowledge about different clinical situations and the different needs of young next-of-kin in these situations are needed to address these dilemmas.

Thus, there is a moral uncertainty regarding the care of these youths involving questions related to the degree of participation in treatment at the ward unit and the information given and whether it may be considered harmful for the young next-of-kin. In addition to the principle of nonmaleficence, care-ethical and family-ethical values are also relevant in the support of young next-of-kin because of the ethical significance of close relationships ${ }^{41}$ and because of how serious illness interferes with family functioning. ${ }^{42}$ Is it best for the youth to stay away or visit their close relative: to stay distant or close to their family member? That is, significant relational ties may be at stake; therefore, it is ethically essential to aim for preserving these ties by facilitating contact and positive visits among parents and children or siblings, despite serious illness and hospital admissions.

\section{Conclusion}

This study demonstrates a need for more systematic knowledge about how young next-of-kin are influenced by the coercive treatment of a close family member. Nevertheless, despite great uncertainty among CRS, the findings provide some indication of the needs of these young people. From the perspective of CRS, better support for young next-of-kin may involve providing more information, developing a more suitable language for talking about coercion and facilitating visits that are positive for both the young person and the patient.

\section{Acknowledgements}

The authors would like to give special mention to the participants for sharing their views and experiences with us. The authors also thank the anonymous reviewers for their valuable and helpful comments.

\section{Conflict of interest}

The authors declared no potential conflicts of interest with respect to the research, authorship and/or publication of this article.

\section{Funding}

The authors disclosed receipt of the following financial support for the research, authorship, and/or publication of this article: This work was supported by the Norwegian Directorate of Health.

\section{ORCID iD}

Elin Håkonsen Martinsen (D) https://orcid.org/0000-0002-9200-1072

\section{References}

1. Sjostrom S. Invocation of coercion context in compliance communication - power dynamics in psychiatric care. Int J Law Psychiatry 2006; 29(1): 36-47.

2. Hallam L. How involuntary commitment impacts on the burden of care of the family. Int J Ment Health Nurs 2007; 16(4): $247-256$. 
3. Kallert TW, Mezzich JE and Monahan J. Coercive treatment in psychiatry: clinical, legal and ethical aspects. Hoboken, NJ: John Wiley \& Sons, 2011.

4. Forde R, Norvoll R, Hem MH, et al. Next of kin's experiences of involvement during involuntary hospitalisation and coercion. BMC Med Ethics 2016; 17(1): 76.

5. Norvoll R, Hem M and Lindemann H. Family members' existential and moral dilemmas with coercion in mental healthcare. Qual Health Res 2018; 6: 900-915.

6. Hem MH, Molewijk B and Pedersen R. Ethical challenges in connection with the use of coercion: a focus group study of health care personnel in mental health care. BMC Med Ethics 2014; 15: 82.

7. Landeweer E, Molewijk B, Hem MH, et al. Worlds apart? A scoping review addressing different stakeholder perspectives on barriers to family involvement in the care for persons with severe mental illness. BMC Health Serv Res 2017; 17(1): 349 .

8. Weimand BM, Sällström C, Hall-Lord ML, et al. Nurses' dilemmas concerning support of relatives in mental health care. Nurs Ethics 2013; 20(3): 285-299.

9. Weimand BM, Hall-Lord ML, Sällström C, et al. Life-sharing experiences of relatives of persons with severe mental illness - a phenomenographic study. Scand J Caring Sci 2013; 27(1): 99-107.

10. Ridley J, Hunter S and Rosengard A. Partners in care?: views and experiences of carers from a cohort study of the early implementation of the Mental Health (Care \& Treatment) (Scotland) Act 2003. Health Soc Care Community 2010; 18(5): 474-482.

11. Martinsen EH, Weimand BM, Pedersen R, et al. The silent world of young next of kin in mental healthcare. Nurs Ethics 2019; 26(1): 212-223.

12. Trondsen MV. Living with a mentally ill parent: exploring adolescents' experiences and perspectives. Qual Health Res 2012; 22(2): 174-188.

13. Kallander EK, Weimand B, Ruud T, et al. Outcomes for children who care for a parent with a severe illness or substance abuse. Child Youth Serv 2018; 39(4): 228-249.

14. Johnson SE, Lawrence D, Perales F, et al. Prevalence of mental disorders among children and adolescents of parents with self-reported mental health problems. Community Ment Health J 2018; 54(6): 884-897.

15. Reupert A and Maybery D. What do we know about families where parents have a mental illness? A systematic review. Child Youth Serv 2016; 37: 98-111.

16. Leijdesdorff S, Van Doesum K, Popma A, et al. Prevalence of psychopathology in children of parents with mental illness and/or addiction: an up to date narrative review. Curr Opin Psychiatry 2017; 30(4): 312-317.

17. Reedtz C, Lauritzen C, Stover YV, et al. Identification of children of parents with mental illness: a necessity to provide relevant support. Front Psychiatry 2019; 9: 728.

18. Siegenthaler E, Munder T and Egger M. Effect of preventive interventions in mentally ill parents on the mental health of the offspring: systemic review and meta-analysis. $J$ Am Acad Child Adolesc Psychiatry 2012; 51: 8-17. e8.

19. Bremnes R. Tvang i psykisk helsevern. Utvikling i perioden 2013-2017 [Use of coercion in mental health services. Development in the period from 2013 - 2017]. Report, Directorate of Health, Oslo, February 2019.

20. Hoyer G. Involuntary hospitalization in contemporary mental health care. Some (still) unanswered questions. $J$ Ment Health 2008; 17(3): 281-292.

21. Monahan J, Hoge SK, Lidz CW, et al. Coercion and commitment - understanding involuntary mental hospital admission. Int J Law Psychiatry 1995; 18(3): 249-263.

22. Lidz CW, Hoge SK, Gardner W, et al. Perceived coercion in mental hospital admission. Pressures and process. Arch Gen Psychiatry 1995; 52(12): 1034-1039.

23. Landeweer EGM, Abma TA and Widdershoven GA. Moral margins concerning the use of coercion in psychiatry. Nurs Ethics 2011; 18(3): 304-316.

24. O'Brien L, Anand M, Brady P, et al. Children visiting parents in inpatient psychiatric facilities: perspectives of parents, carers, and children. Int J Ment Health Nurs 2011; 20(2): 137-143. 
25. Ruud T, Birkeland B, Faugli A, et al. Barn som parørende. Resultater fra en multisenterstudie [Children with ill parents. Results from a multi-center study]. Report, Akershus University Hospital, Lørenskog, November 2015.

26. Wynn R. Involuntary admission in Norwegian adult psychiatric hospitals: a systematic review. Int J Ment Health Syst 2018; 12: 10.

27. Norwegian Ministry of Health and Care Services. Mental Health Care Act of 1999.

28. Norwegian Ministry of Health and Care Services. Health Personnel Act of 2001.

29. Norwegian Ministry of Health and Care Services. Specialist Health Service Act of 2001.

30. Kidd PS and Parshall MB. Getting the focus and the group: enhancing analytical rigor in focus group research. Qual Health Res 2000; 10(3): 293-308.

31. Stewart DW, Shamdasani PN and Rook DW. Focus groups. Theory and practice. London: Sage, 2007.

32. Krueger RA and Casey MA. Focus groups. A practical guide for applied research. 5th ed. Los Angeles, CA: Sage, 2009.

33. Kvale S and Brinkmann S. Interviews: learning the craft of qualitative research interviewing. 3rd ed. London: Sage, 2015.

34. O'Reilly K. Key concepts in ethnography. Los Angeles, CA: Sage, 2008.

35. Elo S and Kyngäs H. The qualitative content analysis process. $J$ Adv Nurs 2008; 62(1): 107-115.

36. Malterud K. Kvalitative metoder i medisinsk forskning: en innføring [Qualitative methods in medical research: an introduction]. 3rd ed. Oslo: Universitetsforlaget, 2011.

37. Malterud K. Systematic text condensation: a strategy for qualitative analysis. Scand J Public Health 2012; 40(8): 795-805.

38. Regional Committees for Medical and Health Research Ethics, https://helseforskning.etikkom.no/ (accessed 15 June 2019).

39. NSD: data protection official for research. Bergen: Data Protection Official for Research, http://nsd.uib.no/per sonvern/en/index.html (accessed 15 June 2019).

40. Beauchamp TL and Childress JF. Principles of biomedical ethics. 6th ed. New York; Oxford: Oxford University Press, 2009.

41. Gilligan C. In a different voice. Cambridge, MA: Harvard University Press, 1982.

42. Nelson HL and Nelson JL. The patient in the family: an ethics of medicine and families. New York: Routledge, 1995. 